\title{
Australia needs to make languages compulsory
}

Edition 7, 2021

Professor Joe Lo Bianco

DOI: 10.37839/MAR2652-550X7.5

Over many decades, governments and others have made commitments to increasing Australia's 'Asia literacy'.

But is this goal being met? Has the growth in investment in language programs and language study seen in the 1980s resulted in lasting change, or is Australia still largely complacent about Asian language education?

Professor Joe Lo Bianco, one of Australia's most respected experts in language education, says if Australia really wants to increase its language literacy-in Asian and other languages-it needs to make language learning compulsory in Australian schools.

Professor Lo Bianco speaks here with Melbourne Asia Review's Managing Editor, Cathy Harper.

You argue that 'in every domain of human endeavour, common shared languages allow us to forge unity across differences, share resources, cooperate and form institutions, economies and nations.' Perhaps there's no greater need for ways to forge unity among and between peoples than during a pandemic, but what effect is COVID-19 having on Asian language education in Australia?

I think COVID is having a deleterious and almost devastating effect on all language education. But I think it has really damaged the our collective efforts in Asian language teaching in a substantial way. A large part of the reason is that language, 
language learning and language study are social practices and deeply interpersonal ones too. Ultimately, for most learners, what is involved in learning a language is the ability to participate in real world conversations. Even though public policy is usually very utilitarian, most language teaching professionals believe in something deeply human associated with language learning and hold the view that language study, even in small ways, makes for a better, more interacting world. I think something of this spirit motivates a lot of people involved in languages, and their commitment to the enterprise of establishing language study as a normal Australian activity is not diminished, in fact, it's increased by the events of recent times.

Yet, here we are in mid-2021 with immense health, economic, and strategic challenges in the region, and our university language programs and area studies are being closed and amalgamated. While I believe the idea of what is defined as the national interest has been too simplistic in the past, I think there is a clear case today that our national interest is being undermined by the erosion of specialist high level research programs on key Asian societies. It seems incredible that in 2021, the absence of guiding policy and unchecked market forces, all aggravated by the effects of COVID, is weakening our national preparation in this way. Just in the past six months we have receded badly, so past vision statements really haven't seeped deeply into the consciousness of our governing classes; and implementation mechanisms, both within institutions and in bureaucracies, have been exposed as fragile and sometimes inept. Very dispiriting on the whole. So in effect I am arguing we need both the substantive humanistic element and the pragmatic strategic dimensions in a comprehensive approach to language.

\section{How can we recover? Are there ways that COVID-19 is helping turn our minds to more innovative ways to teach languages?}

Recently, with some colleagues I did a project exploring the agency of young people in Asian language study. We arranged for a group of Melbourne students to 'organically' teach English to age-peers in China and then to receive lessons from them in Mandarin Chinese. We observed how they conceived and managed the 
activity, the relationships they forged, what their theory of teaching and learning was. One future direction must be to build on the affinity and normalisation that young people have with communications technology. We need to innovate in ways that allow students more direct voice and presence in language teaching designs. A lot of the routine work that teachers would have done in the past will increasingly be redundant through Artificial Intelligence systems. Teachers' roles will shift towards providing personalised and targeted problem-solving guidance and helping students to plan their own learning. If education authorities are responsive to these new possibilities we will be able to greatly expand opportunities for students to listen to real-time naturalistic language from the authentic contexts in which it's generated. Teachers' roles will remain essential, but will be transformed into guidance and management of learning rather than being the complete and sole input. I feel very excited about such prospects even though I don't see much experimentation on an ambitious scale yet.

\section{Is the situation in Australia in terms of language learning and policy better or worse now than it was 30 years ago, after what you've called a 'policy-parade' of changing policy?}

I don't think it can be said to be better or worse-it's really different. Thirty years ago we didn't know a lot of what we know today, such as that relying on target setting doesn't work. Reflecting specifically on Asian languages, I wrote a brief paper called 'Tempted by targets, tempered by results', making the argument against the policy models of the past, especially the practice of directive targets such as 'by X date we want 42 percent or 50 percent of Year 12 students to know an Asian language at University level proficiency'. There have been targets like these issued repeatedly since 1994 and every single one has failed. Are we going to persist with this approach, or are we going to honestly reflect on the modest gains and failures, ask tough questions, and admit that imposing targets on education systems is a flawed outsider's way to make language policy?

What has happened historically? Between 1995 and 2000 when the first NALSAS 
(National Asian Languages and Studies in Australian Schools Strategy) was put in place, close to \$500-million was invested into Asian languages. Precise, timed targets governed the funding allocations. No language teaching effort in Australian history has ever received that much support. It is crucial to ask what was achieved for that huge amount of money and the target centred method of its allocation? I find many people want to avoid facing these questions. A big problem with this approach is that it is 'exotic' or external to the culture of education and its professionals, and external pressure with dedicated funding often leads to forms of superficial compliance, rather than deep change. That's not all that happened, there were many valuable successes, but in relation the investment the outcome was disappointingly small.

The problem with most language policy is that it's been written by people who have very little connection with ordinary schools and teachers, and are exotic to the pressures, functioning and realities of Australian public education. Some policies read like what your trade diplomat or a couple of top business people who spend a bit of time in Taipei or Tokyo say should happen. These voices have a legitimate role in helping shape what should be done, but overreliance on them, as has occurred over and over, produces many problems, but it's just not the case that many students in schools think about trade deals or imagine themselves engaged in their negotiation.

If educators have more prominence in policy design and argument, the logic would be more grounded on the benefits of learning: the cultural and intellectual benefits of learning the languages of our regional neighbours and the practical constraints of ordinary schools, with their competing demands, the identities and experiences of students.

I don't want to be too negative because I think some of what we've done in Asian language education in Australia has been phenomenally successful and important. I think Japanese is the best example. The first policy recognition and funding for Asian languages was in the National Policy on Languages of 1987. By 1990 we had 
secured the presence of Japanese in many parts of Australia, and began the process of 'Australianising' its teaching and learning. I recognise now that it is an unfortunate term, but at the time we called it the 'tsunami' of interest in Japanese, and it proved durable and hugely successful. Some simple sounding ideas governed what was done: support the teachers, build the training, encourage a culture of acceptance in schools, cooperate across curriculum areas, link it to literacy, link it to what else is going on in the curriculum, resist external characterisations from 'outside elites' pushing unintegrated practices onto the culture of schooling. Today we can see that Japanese is a very well-established language-it's the most widely taught language in the country and it has been for many years and it's the most widely taught language at secondary level. If we aggregate all levels of education, Japanese and Italian are more or less equal. Australian Japanese teaching and learning is a big success story and has been for many years.

I think the same is true of Indonesian, but with several caveats. Sadly, today we see that Indonesian is experiencing turmoil in several jurisdictions, and this must be redressed, but in some systems the performance of Indonesian is robust and promising - this is the case in Victorian primary schools.

\section{Is Australia still largely a monolingual country?}

I think the truth is more nuanced. Our national institutions and dominant social practices-most media, sport, legal and medical domains-are overwhelmingly monolingual in English, and we have an elite class that's largely monolingual. Our decision making classes are not just monolingual in speaking only one language they are also monolingual in their thinking - they think that monolingualism is the normal condition of humanity and of efficiently functioning societies. The reality is very different: multilingualism and multilingual thinking and behaviour are and always have been the 'normal human condition', to put it grandly.

Away from our institutional monolingualism we see that Australia is in reality a vastly multilingual society. The immense European migration of the Second World 
War is an established mainstream community element. Many of these communities work hard to keep their languages alive. For several decades I have been working on language policy in Southeast Asian countries, recently mostly in Myanmar. Some people in these countries still have an image of Australia as Anglo, white and monolingual. But we know Australia has long received enormous migration volumes from all across Asia, these are people I know, work with, live next to, socialise with etc. Their families in Asia whom I visit and also know don't think Australia is an exclusively monocultural monolingual society because the evidence is present in their family networks; yet their characterisation of 'the country' is Anglo, white, and monolingual. It's important that we don't lose sight of this 'bifurcated' reality of Australia, the difference between the people-to-people relations of current globalisation and mobility, the reality of Australia as a deeply multicultural multilingual society, and the contrast with the mentality and image of institutional monolingualism.

\section{Do you think our Asian neighbours' view of Australia as being Anglo and monolingual is perhaps related to the pluralism that is present within their own countries and the extent to which their own countries support language learning?}

Few Asian countries support the language rights of their minority communities, and most foreign language study is directed to English. In most Asian countries there isn't much teaching about Asia either. I've looked at the curriculum in Thailand, Indonesia, Malaysia and ASEAN more generally, which has been promoting regional studies, and most of this is done in English, though there are more and more curriculum units devoted to ASEAN countries and their social and political make up. But the curriculum in most countries tends to be nation-centred-not nationalistic, but focused on the nation (as ours is too, we focus on Australia). I don't think there's anything wrong with this, oriented as it must be towards cultivating informed citizenship, but I think it's not true to think that Australia is a country that stands out by denying its minorities, whereas other countries embrace them. There are experiments with multilingual education in Thailand, there are the beginnings of 
support for Indigenous minority languages in Vietnam and Cambodia, but for many decades this was not the case. In Laos, for example, there is no openness to teaching minority languages. By contrast, Malaysia and Indonesia do offer many kinds of language support, and in recent years the Philippines has embraced forms of Indigenous language teaching that are groundbreaking in world terms. Sadly, in the very recent past there has been and erosion of this commitment there. Though there is some opening to language differences in Japan, both it and South Korea have been tentative about embracing multiple language teaching. In recent years Taiwan has invested a great deal in new policies for supporting its many Indigenous populations.

India is an exemplary case of multi-lingual policy. Its Constitution recognises 22 scheduled languages plus English and Hindi as across-the-country languages. In the south people often prefer English to Hindi, but most states support both and often a unique state language as well. In recent years, with the adoption of the Right to Education Act, India is moving to support sub-national tribal language groups (Adivasi) but the picture differs greatly across the country.

I've always been optimistic about the Australian context because I know that in most countries there is less openness to minority languages and languages in general than there is in Australia. One of the great successes of our language policies has been to improve general attitudes. People used to say, 'the world needs one language', 'we're lucky to be an English-speaking country', 'migrant languages should fade away', 'Aboriginal languages are inferior'. The systemic prejudice against Indigenous languages has also faded, but when I started in language policy work it was deeply prevalent and very shocking, there was so much racism-a lot more racism than there is now about language issues and it was coupled to a strong sense of the superiority of English. I grew up in a small rural town in the 1950s and 1960s, enough said. It is now some decades that the best performing and most competitive economies in the world have been in Asia. One effect of this is that fewer people exhibit the level of Anglo complacency that I recall when I first started interviewing political and economic leaders about language policy in the early 1980s. This 
superiority was pervasive and we shouldn't forget it, but the fact it's now largely gone is a big achievement for our country.

\section{To what extent do you think the vicissitudes of language teaching in Australia have been related to bi-lateral tension, such as most notably recently with China?}

It is true that language study is buffeted by international relations, but it's not necessarily lasting. We need to keep in mind that this happens to all languages. During the decades when there was French nuclear testing at Mururoa Atoll and other French territories in the Pacific there was anti-French protest in this country and some of this was directed against the language and its teaching. Directing political protest at language teaching efforts is a conflation of foreign government policy with domestic language teaching. Unfortunately, we've seen anti-Asian racism in Australia in the last year precisely because some people don't distinguish between global political events and the rights of their fellow citizens. It's a sad fact, but it recalls the point I was making earlier about our institutional blindness to our essential multiculturalism. Governments should anticipate these things, just like we have seen with COVID-19 communications and our public authorities operating with a monolingual mindset. This used to be much better once. We have regressed in some ways.

As far as Chinese is concerned, if Year 12 performance can be taken as a useful indicator Chinese is flourishing, attracting students and being promoted. We have had a generally responsive curriculum planning process, so that Chinese is offered at three levels (much better than how Chinese language programming is delivered in most countries in the world) and this allows us to accommodate students who are literate and fluent speakers of the language, to complete beginners, and to the large cohort in the middle who might be speakers of another Chinese dialect or who are Australian-Chinese and may be dominant in English. It will take more time to ascertain if current tensions between Australia and China have a negative impact on the study of the language. I hope not. Australia urgently needs a more systematic 
policy for Chinese high proficiency, but I don't see that as being a school-based initiative necessarily.

\section{You've said before that 'serious language study that produces reasonable standards of proficiency and intercultural capability should be considered a key 21 st century literacy.' If you were in charge of policy making, what would you do?}

I think four things need to be done. First, languages need to be made compulsory; which in Victoria they are practically at this point, but not in most other jurisdictions. This is especially disappointing in New South Wales which is the biggest state with a strong multicultural community presence and a lot of community organisations delivering 'bottom up' language programming, and yet in formal education language policy is really limited. Most jurisdictions would not have the resources to deliver compulsory and universal language teaching right away, but this should be established as a principle and goal.

The second priority action is the development of integrated language teaching practices that link into other subject areas, either through content and language integration, or through active collaboration between subject teachers and language teachers. We did this in Japanese in some schools with targeted activities examining the Fukushima tsunami and earthquake in 2011-2012-working directly with students on real life research, presentations and studies linked across the curriculum (geography, environment, society) to Japanese language and current events. At first such integration across curriculum areas can be challenging for nonlanguage teachers, in this case the geography and the social sciences teachers, who must accept that content from their area will be dealt with in the language class and accept that this will be different from the specialist approach they would use. The students' Japanese language abilities for dealing with real world content needs to be explicitly built up and supported, and there may be some reliance on English at times. The effect of these approaches, and in this specific example also, was to generate a highly motivating program for students, dealing with something real and 
topical. It was very motivating and recognised the existing knowledge of students. The non-language subject teachers became enthusiastic and committed to the innovation as it progressed, recognising how it reinforced rather than undermined what they were doing in their subjects. The Japanese teacher could direct attention on specific items of language and activate students' interest and current knowledge. These are all good language learning principles. Innovations of this kind need to be planned and executed carefully, addressing problems as they arise, and sustained because they deliver good results in language, subject content and motivation, and help to integrate language programs into general educational activity, thereby securing their future.

The third thing is much more investment is needed to build new teacher professional development; and the fourth priority is, as mentioned earlier, a much richer exploration of what the technology offers us.

I also think we need to 'multiculturalise' our curriculum in general. There's a lot of effort currently in injecting Asian perspectives into general curriculum work, but we must go deeper. Given the radical changes in what counts as literacy that will flow from the revolution in Artificial Intelligence literacy, we need to re-think general educational practices, pluralise perspectives so that students come to see difference as a normalised expectation in life to be negotiated, understood and accepted, and to develop skills in intercultural interaction. The post-COVID world will intensify patterns of interaction that have been developing for some time but are now more mainstream, a much more richly interactive global world of mobilities. People, of diverse social classes, will space parts of their lives in Hong Kong, then Frankfurt for six years, for example, and children will have ongoing virtual lives online and interactively, and a large part of their learning will be structured there.

Banner image: Chinatown, Melbourne. Credit: Christoph Settgast/Flickr. 